\title{
INFLUENCIA DE LOS ESCENARIOS PEDAGÓGICOS: AULA DE CLASE Y LABORATORIO EN EL PROCESO DE ENSEÑANZA-APRENDIZAJE DE LAS CIENCIAS NATURALES
}

\author{
Diana Lucía Cuaical Cuaical ${ }^{1}$ \\ diana-luc0193@hotmail.com \\ Diana Maribel Cuesta Caicedo ${ }^{2}$ \\ Grupo de Investigación Historia, \\ Educación y Desarrollo - HISED \\ diancuesta@hotmail.com
}

\begin{abstract}
Resumen
El presente artículo de reflexión es resultado de un Trabajo de grado ${ }^{3}$ realizado en colectivo y hace especial énfasis en la influencia que tienen los escenarios pedagógicos en este caso: aula de clase y laboratorio y las estrategias didáctico-pedagógicas empleadas por el docente para la enseñanza del área de Ciencias Naturales, esto con el propósito de comprender como las condiciones físico ambientales, organización y recursos didácticos que presentan los escenarios pedagógicos facilitan el proceso de enseñanza-aprendizaje del área en mención, para ello se empleó la técnica de observación directa que permitió caracterizar las aulas de clase y laboratorios, con respecto a las estrategias didáctico-pedagógicas se utilizó entrevista a docente y estudiantes, y guías de observación de clase.

Así pues, este trabajo permite identificar que las características de las aulas de clase y laboratorios influyen en el ambiente de aprendizaje de
\end{abstract}

1. Licenciada en Educación Básica con Énfasis en Ciencias Naturales y Educación Ambiental.

2. Licenciada en Educación Básica con Énfasis en Ciencias Naturales y Educación Ambiental.

3. Trabajo de grado titulado "Influencia de los escenarios pedagógicos: aula de clase y laboratorio en el proceso de enseñanza-aprendizaje de las ciencias naturales", realizado en colectivo como requisito para optar al título de Licenciadas en Educación Básica con Énfasis en Ciencias Naturales y Educación Ambiental. 
las ciencias naturales, en este sentido, el aula de clase al ser el espacio utilizado con mayor frecuencia para el desarrollo de las clases posibilita la aplicación de diversas estrategias de enseñanza, sin embargo, limita el desarrollo de actividades experimentales. Por su parte, los laboratorios cuentan con las condiciones y recursos propicios para llevar a cabo este tipo de actividades, por ello es importante alternar el trabajo de aula haciendo uso de los diferentes espacios con los que cuentan las Instituciones Educativas, lo anterior con el fin de propender por diversidad de ambientes de aprendizaje que generen interés por parte de los estudiantes.

Palabras clave: Escenarios pedagógicos, estrategias de enseñanza, recursos didácticos, enseñanza-aprendizaje.

\title{
INFLUENCE OF PEDAGOGICAL SCENARIOS: CLASSROOMS AND LABORATORIES IN THE LEARNING PROCESS- LEARNING NATURAL SCIENCES
}

\begin{abstract}
This article emphasizes the influence of the classroom and the laboratory as pedagogical scenarios, as well as the didactic-pedagogical strategies used by teachers to teach Natural Sciences. The investigation offers understanding of how different conditions, such as the physical environmental, organization, and didactic resources present in the pedagogical scenarios facilitate the teaching-learning process of the aforementioned area. Using direct observation techniques, the classrooms and laboratories were characterized with respect to teaching strategies. Pedagogical interviews were conducted with teachers and students, and class observation guides were administered.

This work allows us to identify that the characteristics of classrooms and laboratories influence the learning environment of the Natural Sciences, and that the classroom is the most frequently used space for the development of classes. Though it allows for the application of various teaching strategies, it limits the development of experimental activities. On the other hand, laboratories provide the conditions and resources to carry out these types of activities, so it is important to alternate in-class work and make use of the different spaces available to educational institutions in order to provide diverse learning environments that generate interest in the students.
\end{abstract}

Keywords: Pedagogical scenarios, learning strategies, teaching resources, teaching- learning. 


\title{
INFLUÊNCIA DE CENÁRIOS PEDAGÓGICOS: SALA DE AULA E LABORATÓRIO NO PROCESSO DE ENSINO - APRENDIZAGEM DE CIÊNCIAS NATURAIS
}

\begin{abstract}
Resumo
Este artigo enfatiza a influência dos cenários pedagógicos tanto a sala de aula Como no laboratório, além de estratégias educativas e pedagógicas utilizadas pelos professores para o ensino da área de Ciências Naturais, este a fim de compreender as condições física ambiental, recursos organizacionais e didáticos que apresentam cenários pedagógicos facilitam a área de ensino-aprendizagem em questão, para isto se utilizou a técnica de observação direta que permitiu caracterizar as salas de aula e laboratorios, utilizados com relação a estratégias didáticas pedagógicas entrevistas foram usadas para professores e alunos, e guias de observação de classe.

Assim, este trabalho permite identificar que as características das salas de aula e laboratórios influenciam o ambiente de aprendizagem das ciências naturais, sendo nesse sentido, a sala de aula o espaço mais utilizado para o desenvolvimento das aulas. permite a aplicação de várias estratégias de ensino, no entanto, limita o desenvolvimento de atividades experimentais. Por sua vez, os laboratórios possuem as condições e recursos para realizar este tipo de atividade, por isso é importante alternar o trabalho em sala de aula fazendo uso dos diferentes espaços disponíveis para as Instituições Educacionais, o precedente, a fim de tender pela diversidade de ambientes de aprendizagem que geram interesse por parte dos alunos.
\end{abstract}

Palavras-chave: Cenários pedagógicos, estratégias de ensino, recursos didáticos,

\section{Introducción}

El presente artículo busca hacer una reflexión sobre el papel que tienen los espacios en la enseñanza-aprendizaje de las Ciencias Naturales y las estrategias que dinamizan este proceso, por ende se resalta los diversos aspectos que influyen en el aprendizaje del estudiante, como las estrategias didácticas, las metodologías y los escenarios donde se desenvuelven los actores educativos, cuyos espacios físicos son visualizados como un lugar para desarrollar una actividad, más no, como escenarios pedagógicos que disponen de condiciones y recursos que propician interacciones entre los estudiantes y docente, promoviendo las articulación en el proceso de enseñanza-aprendizaje.

Para las autoras se denominan escenarios pedagógicos el aula de clase y el laboratorio, puesto que en estos espacios se lleva a cabo la enseñanza-aprendizaje 
de las ciencias naturales. En este orden de ideas se caracterizan los escenarios, teniendo en cuenta las condiciones físico-ambientales, la distribución del mobiliario, los recursos didácticos y las estrategias utilizadas por el docente; todos estos aspectos hacen que el estudiante interactúe directamente con el docente y los recursos del entorno educativo, los cuales contribuyen al aprendizaje de las ciencias naturales.

Los hallazgos importantes que se encontraron fueron: en primer lugar que las condiciones físico-ambientales que tienen los escenarios pedagógicos en especial las aulas de clase son escasamente adecuadas, pues poseen baja iluminación y ventilación; con respecto a los laboratorios, estos escenarios presentan buenas condiciones, sin embargo, la disposición de los recursos y mobiliario no es apta para la movilidad de los estudiantes.

Así mismo, se encuentra que las estrategias mediante las cuales se llevan a cabo los procesos de enseñanza-aprendizaje de las ciencias naturales se enfocan principalmente al desarrollo las clases de manera teórica, por ejemplo se emplea la contextualización mediante la ejemplificación, la explicación oral, la pregunta y el empleo de videos, de ello se infiere que no se desarrollan estrategias que permitan al estudiante confrontar y observar lo que aprende a través del hacer en los escenarios pedagógicos, pues es el docente el encargado de utilizarlos y convertirlos en escenarios que posibilitan el aprendizaje a través de sus propuestas innovadoras y creativas.

\section{Metodología}

La metodología que se empleó para el desarrollo de la investigación se basa en el paradigma cualitativo, bajo el enfoque crítico social y tipo de investigación acción. Así pues, la unidad de trabajo que hizo parte de esta investigación estuvo conformada por el docente del área de ciencias naturales y 40 estudiantes de grado noveno escogidos de manera aleatoria, puesto que todos se encontraban con disposición para colaborar en el proceso investigativo. La recogida de información se realizó a través de técnicas como la observación directa, encuesta y entrevista dirigida al docente y estudiantes.

\section{PLANTEAMIENTO DEL PROBLEMA}

De la investigación realizada en la Institución Educativa Liceo Central de Nariño, se logró evidenciar que el aula de clase tiene mayor prioridad a la hora de desarrollar el plan de estudios propuesto para las ciencias naturales, no ocurre lo mismo con el laboratorio, debido a que este es escasamente utilizado como escenario de aprendizaje, por lo tanto los estudiantes no tienen la oportunidad de realizar actividades de experimentación.

En ese orden de ideas, las autoras se plantearon el siguiente interrogante ¿Cómo los escenarios pedagógicos: aula de clase y laboratorio facilitan los procesos de enseñanza- aprendizaje del área de ciencias naturales en los grados novenos de la IEM Liceo Central de Nariño? Atendiendo a Zabalza (citado en Vílchez, 
Hidalgo, Silva, Maza), quien dice que "una escuela de calidad ha de disponer, de espacios y tiempos para el desarrollo de "experiencias fuertes", que dejen huella [...] lo que ocurre cuando se propone al niño algo distinto, capaz de captar y envolver su atención"4. La investigación tiene como objetivo general analizar cómo los escenarios pedagógicos facilitan el proceso de enseñanza-aprendizaje del área de ciencias naturales, para ello fue necesario Caracterizar los escenarios pedagógicos, aula de clase y laboratorio, así mismo identificar las estrategias didácticas utilizadas para la enseñanza del área de ciencias naturales.

\section{DESARROLLO}

\subsection{Concepción de escenarios pedagógicos}

Se considera importante decir que, "la trama entre el docente, el alumno y el conocimiento enunciados en un lugar, lugar como concepto que designa a un territorio dinámico en donde se especializa, toma forma y discurre la relación entre los tres protagonistas nombrados"5. Teniendo en cuenta la importancia que tiene este "lugar" como lo menciona Medina, las autoras de la investigación consideran denominar a éste como "escenario pedagógico" por las razones que se explicitan a continuación. En primera instancia se pone en consideración la siguiente analogía:

"Si los guiones son una característica importante de la producción de una obra, también existen otras cosas que deben considerarse. El escenario es una parte importante en cualquier producción dramática. Proporciona el telón contra el cual se actúa la obra. El diseño del decorado determina donde y como se pueden mover los actores alrededor del escenario. Una alteración en este último puede generar un cambio en el ánimo del auditorio. Hay muchos significados simbólicos en el escenario de una producción dramática; parte del mensaje que cualquier obra trasmite el auditorio se hace por medio de la escena que se establezca. Igualmente, cuando los maestros planean sus clases, comunican un mensaje en su manera de organizar la escena para la clase, así como en lo que les dicen o piden a los alumnos que hagan durante la misma. El escenario del maestro es el salón y el decide la escena al arreglar el espacio físico del mismo. Además, el maestro dispone la escena para las clases por medio de la determinación de la organización social del salón. En una "escena” bien diseñada, las organizaciones física y social se complementan mutuamente"6.

4. Verónica Vílchez Garrido et al., El aula: Un espacio de posibilidades: arte, educación y cultura (España: Colbaa, 2012), http://www.educacionartistica.es/aportaciones/4_audiovisuales/402_silv_maz_hid_ vilch_cab_aula\%20espacio\%20de\%20posibilidades.pdf (10 de junio de 2015).

5. Jorge Medina. El malestar de la pedagogía. El acto de educar desde otra identidad docente (Argentina: Ediciones novedades educativas, 2006), https://books.google.com.co/books?id=HETri-bB9tIC\&pg=P A53\&dq=acto+pedagogico\&hl=es-419\&sa=X\&ved=0CBwQ6AEwAGoVChMI7YvpnZLMxwIVxtgeCh2J WATL\#v=onepage\&q=acto\%20pedagogico\&f=false (22 de junio de 2015)

6. James Cooper, Estrategias de enseñanza: Guía para una mejor instrucción (México. D.F.: Editorial Limusa. S.A, 2004), 75. 
Con base en esta analogía, el aula de clase no es meramente un espacio físico cualquiera, sino que se convierte en escenario, cuando en él se desarrolla la planeación de la clase, cuando dispone de materiales para desarrollar dicha planeación y cuando la disposición física de sus recursos influye en el desarrollo del proceso educativo.

En ese sentido, se convierte en escenario pedagógico, cuando dispone de condiciones y recursos propicios para desarrollar diferentes escenas que en el salón de clase pueden ser interpretadas como las interacciones que se establecen entre los actores educativos. Para sustentar, Parras (citado en Duarte) plantea que: "el ambiente educativo remite al escenario donde existen y se desarrollan condiciones favorables de aprendizaje. Un espacio y un tiempo en movimiento, donde los participantes desarrollan capacidades, competencias, habilidades y valores"7.

Por tal razón, la formación del educando no sólo depende de la calidad de enseñanza brindada sino también de los escenarios pedagógicos en los cuales haya interactuado y convivido, los cuales deben ser adecuados con los procesos educativos, de modo que cuenten con las condiciones y recursos necesarios que coadyuven a generar un ambiente de aprendizaje propio de las ciencias naturales, donde la investigación e interacción con el mundo natural sean prioritarias.

\subsection{1 ¿Qué se entiende por aula?}

"Tradicionalmente el "aula" o salón de clases es aquel entorno físico-humano donde se desarrolla la enseñanza institucionalizada y donde realizan sus actividades los dos actores principales del proceso de enseñanza y aprendizaje, el educador y el educando [...] Esta, no sólo es el escenario físico donde se efectúa el trabajo pedagógico de la escuela, sino fundamentalmente es un ámbito socio afectivo donde se produce el encuentro y la interacción entre los dos protagonistas del proceso educativo". ${ }^{8}$

Iglesias (citado en Vílchez et al) plantea que el aula es un "cúmulo de recursos de aprendizaje y desarrollo personal" ${ }^{\prime}$. Por lo cual, se entiende que el aula es el espacio donde se llevan a cabo los procesos de enseñanza aprendizaje, el cual debe presentar las condiciones necesarias para que el proceso pedagógico se desarrolle satisfactoriamente y donde el estudiante tenga las herramientas necesarias que faciliten su aprendizaje y también, el docente utilice recursos que generen el

7. Jakeline Duarte, "Ambientes de aprendizaje. Una aproximación conceptual", Estudios pedagógico. No. 29 (2003): 97-113. http://www.scielo.cl/scielo.php?script=sci_arttext\&pid $=$ S0718-07052003000100007 ( 6 de mayo de 2014).

8. Vílchez et al., "El aula: un espacio de posibilidades: arte, educación y cultura". (España: Colbaa, 2012), http://www.educacionartistica.es/aportaciones/4_audiovisuales/402_silv_maz_hid_vilch_cab_ aula\%20espacio\%20de\%20posibilidades.pdf (10 de junio de 2015).

9. Vílchez, et al., "El aula: un espacio de posibilidades: Arte, Educación y Cultura" (España: Colbaa, 2012), http://www.educacionartistica.es/aportaciones/4_audiovisuales/402_silv_maz_hid_vilch_cab_ aula\%20espacio\%20de\%20posibilidades.pdf (10 de junio de 2015). 
interés por parte de sus alumnos y de esta manera, las clases sean ambientes innovadores y facilitadores de conocimiento. De ahí que:

"Un aula propia significa que puede crear una atmósfera que refleja el carácter del docente; y que se le ofrece a los alumnos que vengan hacia él; le permite usar exposiciones en la paredes como ayudas didácticas; significa que puede utilizar mejor las ayudas prácticas de materiales educativos, tiene fácilmente a mano el trabajo de los alumnos y nunca necesita ir en busca de algo; y significa, por encima de todo que puede utilizar el ambiente físico del aula como un aliado para influir sobre el alumno [...] no solo el aula bien cuidada y estéticamente agradable, con disponibilidades funcionales, es educativa en si misma sino que también los alumnos se comportan mejor en una clase bien organizada"10.

De lo antedicho, se puede inferir que el aula, además de ser el lugar donde conviven tanto docente como estudiantes, se considera como un recurso que el docente puede utilizar para el desarrollo de sus clases y generar nuevos ambientes de aprendizaje, asimismo, el aula debe ser el lugar donde el estudiante participa activamente sin necesidad de condicionar su autonomía y libertad al momento de aprender.

\subsection{2 ¿Qué se entiende por laboratorio?}

Según los lineamientos curriculares del área de ciencias naturales el laboratorio es concebido como:

"El sitio donde se diseña la forma de someter a contraste las idealizaciones que hemos logrado acerca del Mundo de la Vida, mediante procedimientos que son concebidos dentro de la racionalidad de estas mismas idealizaciones y que tienen la misión de proveer elementos de juicio para tomar una decisión acerca de la objetividad de estas idealizaciones. En otras palabras, en el laboratorio podemos encontrar los argumentos de mayor peso para poder argumentar ante la comunidad científica la necesidad de refutar o confirmar la teoría que explica la clase de fenómenos a la cual pertenece lo observado en el laboratorio. Sin esas idealizaciones, sin un marco teórico que le dé al estudiante la posibilidad de observar, el experimento en el laboratorio es una actividad enteramente superflua"11.

Así pues, el laboratorio para la enseñanza de las ciencias conlleva a que el estudiante adquiera conocimientos a través de la práctica, experimentación y demostración de los fenómenos, sin embargo es conveniente que el docente plantee de manera anticipada las estrategias, técnicas y metodologías a desarrollar,

10. Michael, Marland. El arte de enseñar: técnicas y organización del aula (España: Morata, 2003), http:// books.google.com.co/books?id=dM4oerVJesMC\&printsec=frontcover\&dq=importancia+del+aula + en+la+labor+educativa\&hl=es\&sa=X\&ei=676UUrh0eipsATp9YCIDQ\&ved=0CCwQ6AEwAA\#v=0 nepage \&q\&f=false (24 de junio de 2015).

11. Ministerio de Educación Nacional. Lineamientos curriculares de las ciencias naturales y educación ambiental (Bogotá: Ministerio de Educación Nacional, 1998), http://www.mineducacion.gov.co/ cvn/1665/articles-89869_archivo_pdf5.pdf (18 de marzo de 2014). 
posibilitando espacios para la comprensión y adquisición de conocimientos mediante actividades prácticas significativas para el alumno, en este sentido el laboratorio es un escenario que permite: "La demostración, la experimentación y el contacto con las realidades tangibles imprescindibles en la enseñanza y aprendizaje de las áreas experimentales [...] es necesario que el planteamiento de prácticas en el laboratorio intente acercar a los estudiantes al trabajo real que los científicos desarrollan en ellos"12.

Por su parte, Dumon (citado en Gallego \& Pérez) señala que, el trabajo en el laboratorio permite que los alumnos sean capaces de: "identificar el problema, plantearse cuestiones y tener ganas de responderlos por sí mismos; formular hipótesis; poner en tela de juicio sus representaciones a partir de los resultados experimentales; buscar la información necesaria para la resolución de problemas. Resolver el problema ideando experimentos"13.

En este caso, cuando el estudiante se desempeña en el laboratorio desarrolla procesos en los cuales debe observar y comprobar las predicciones que haya establecido frente a un determinado fenómeno, además, le posibilita articular sus conocimientos previos con las teorías ya establecidas, dando lugar a la comprensión y aplicación de sus conocimientos en el contexto que lo rodea.

\subsubsection{Características de los escenarios pedagógicos para la enseñanza de las ciencias naturales}

En el contexto educativo es importante tener en cuenta los actores que forman parte de éste, como son: el docente, estudiante y los contenidos que serán desarrollados durante el proceso de enseñanza - aprendizaje de las Ciencias Naturales. De esta manera, es conveniente hacer hincapié en los espacios físicos donde se desarrollan las clases, así pues, las autoras mediante la técnica de observación directa caracterizaron los escenarios pedagógicos: aula de clase y laboratorio, teniendo en cuenta las condiciones físico - ambientales, los recursos y la organización de los mismos.

\section{Condiciones físico-ambientales de los escenarios pedagógicos.}

En cuanto a las condiciones físico -ambientales de las aulas de clase; estas presentan características semejantes, es decir, se observa que el tablero, puertas y ventanas no están en buen estado puesto que presentan manchas y ralladuras, además, las ventanas siempre permanecen cerradas, limitando la ventilación en estos lugares. Por su parte, los laboratorios con los que cuenta la Institución

12. Mario Díaz. Metodologías de enseñanza y aprendizaje para el desarrollo de competencias: Orientaciones para el profesorado universitario ante el espacio Europeo de educación superior (Madrid: Alianza. Editorial S.A, 2006), 88.

13. Rómulo Gallego y Royman Pérez. La enseñanza de las ciencias experimentales: El constructivismo del caos (Santafé de Bogotá, D.C: Cooperativa Editorial Magisterio, 1997), 264-265. 
Educativa presentan condiciones adecuadas que facilitan el desarrollo de las actividades académicas del área de ciencias naturales.

Por lo anterior, se cita a Titone (1996) quien menciona que: "Las condiciones físicas determinan el ambiente interno del aula constituido por elementos de iluminación, calefacción, ventilación, por el mobiliario y el material".14 Por lo anterior, es necesario que los espacios, en este caso las aulas al ser un lugar primordial para el desarrollo del estudiante deben contar con las condiciones propicias, al respecto: Knapp (citado en Cerda) dentro de sus investigaciones afirma que:

"La mayoría de las aulas en Estados Unidos [...] tienen amplias ventanas que dejan pasar la luz entre los hombros de los estudiantes. Este emplazamiento de las ventanas determina la dirección en que los estudiantes han de mirar y por tanto el frente de la clase [...] las críticas se centran en la debilidad de la iluminación, lo cual dificulta la lectura de la letra pequeña, la pobreza de la acústica que impide la audición del profesor en determinados lugares del aula [...] todos estos factores que a juicio del autor, son determinantes en el rendimiento del estudiante y afectan el comportamiento de este"15.

La institución educativa cuenta con dos laboratorios uno de física y otro de ciencias naturales empleado para el desarrollo de clases de química y biología, los cuales presentan las siguientes características: ventanas amplias que ocupan la mayor parte de una de las paredes, ventanillas localizadas en la parte superior que permanecen abiertas, también cuenta con lámparas que iluminan el espacio, 5 mesones dispuestos en el centro del laboratorio cada uno con llaves de agua y gas, cuyos conductos se encuentran ocultos, 2 puertas de acceso, pero una de ellas se encuentra obstaculizada por un tablero. Así pues, los laboratorios presentan semejanzas en lo que se refiere a ventilación e iluminación, pues cuentan con ventanas amplias en buenas condiciones que favorecen la entrada de luz y aire, debido a que las ventanillas siempre se mantienen abiertas.

A raíz de ello Gaviño, Juárez \& Figueroa plantean que las principales instalaciones por considerar en el laboratorio son:

"La calefacción, la ventilación, el desagüe y la provisión de agua, gas y electricidad; respecto a ventilación y calefacción, puede ser natural o artificial, debe evitarse la formación de corrientes de aire, ya que pueden perjudicar no solo el material de estudio sino también al personal que trabaja en el laboratorio [...] debe tenerse en cuenta ante todo, que la iluminación sea adecuada, dispuesta convenientemente en relación con las mesas de trabajo, la iluminación puede ser natural o artificial. La más conveniente, por su intensidad es la luz natural, pero debe evitarse luz solar directa que forme reflejos molestos a la observación o altere la temperatura del laboratorio [...] Es necesario que los conductos para los

14. Renzo Titone, Metodología didáctica (Madrid: Editorial RIALP, 1966), 545.

15. Hugo, Cerda, Proyecto de aula: el aula como un sistema de investigación y construcción de conocimientos (Santafé de Bogotá: Cooperativa Editorial Magisterio, 2001), 28. 
cables eléctricos, gas, agua, sean accesibles y estén fuera de los lugares de paso y además, que llegue por instalaciones ocultas, para que no obstruyan la superficie de las mesas"16.

Por otra parte, el laboratorio de física, dispone de una bodega para el almacenamiento de los materiales de experimentación, en cambio el laboratorio de ciencias naturales posee dos bodegas, una de ellas empleada únicamente para los reactivos y materiales de cristalería y la otra contiene distintos materiales educativos, caracterizándose por su disponibilidad y fácil acceso.

De acuerdo a lo anterior los laboratorios presentan las características que menciona el autor, de ello se infiere que estos espacios cumplen con las condiciones mínimas para llevar a cabo un proceso de enseñanza-aprendizaje acorde a los contenidos de las ciencias naturales, sin embargo, se encuentra que estos lugares no son utilizados con frecuencia desaprovechando las ventajas que estos poseen.

\section{Organización de los escenarios pedagógicos}

A la luz de Loughlin \& Suina "la organización del espacio en el ambiente de aprendizaje empieza con la disposición del mobiliario que divide el área total del aula en zonas más pequeñas. Algunos espacios son diseñados por el profesor, pero otros, creados sin intención, pueden pasar inadvertidos. Como la organización espacial influye en las acciones y otras conductas, las áreas desapercibidas, pueden respaldar o contradecir los propósitos y expectativas del profesor respecto de la conducta infantil"17.

De lo anterior, se dice que la distribución que se haga de los recursos existentes en el aula como en el laboratorio favorece u obstaculiza las actividades planteadas por el docente. En este sentido, la disposición adecuada de los recursos hace de los escenarios unos espacios dinamizadores del proceso de enseñanza - aprendizaje, donde la labor del docente consiste en generar ambientes agradables e innovadores que cautiven en el estudiante el deseo por aprender, como lo menciona Loughlin \& Suina:

"El ambiente de la clase es mucho más que un lugar para almacenar libros, mesas y materiales. Cuidadosa y diestramente dispuesto, añade una dimensión significativa a la experiencia educativa del estudiante, atrayendo su interés, brindando información, estimulando el empleo de destrezas, comunicando límites y expectativas, facilitando las actividades de aprendizaje, promoviendo la propia orientación y respaldando y fortaleciendo a través de estos efectos el deseo de aprender"18.

16. Gaviño Gonzalo et al., Técnicas biológicas selectas del laboratorio y de campo (México: Editorial Limusa, 1994), 11-12.

17. Catherine Loughlin y Joseph Suina, El ambiente de aprendizaje: Diseño y organización (Madrid: Editorial Morata, S.L, 1995), 67.

18. Loughlin y Suina, El ambiente de aprendizaje: Diseño y organización, 16. 
Así pues, en cuanto a mobiliario y equipamiento de las aulas de los grados novenos, se encontró que éstas presentan similitud en el número y distribución de los pupitres y escritorios los cuales se ubican frente al tablero y escritorio del profesor. En efecto, es evidente que la organización de los salones de clase aún corresponde a una visión tradicional, puesto que los pupitres se ubican uno tras otro formando filas, organización que se mantienen durante la jornada escolar.

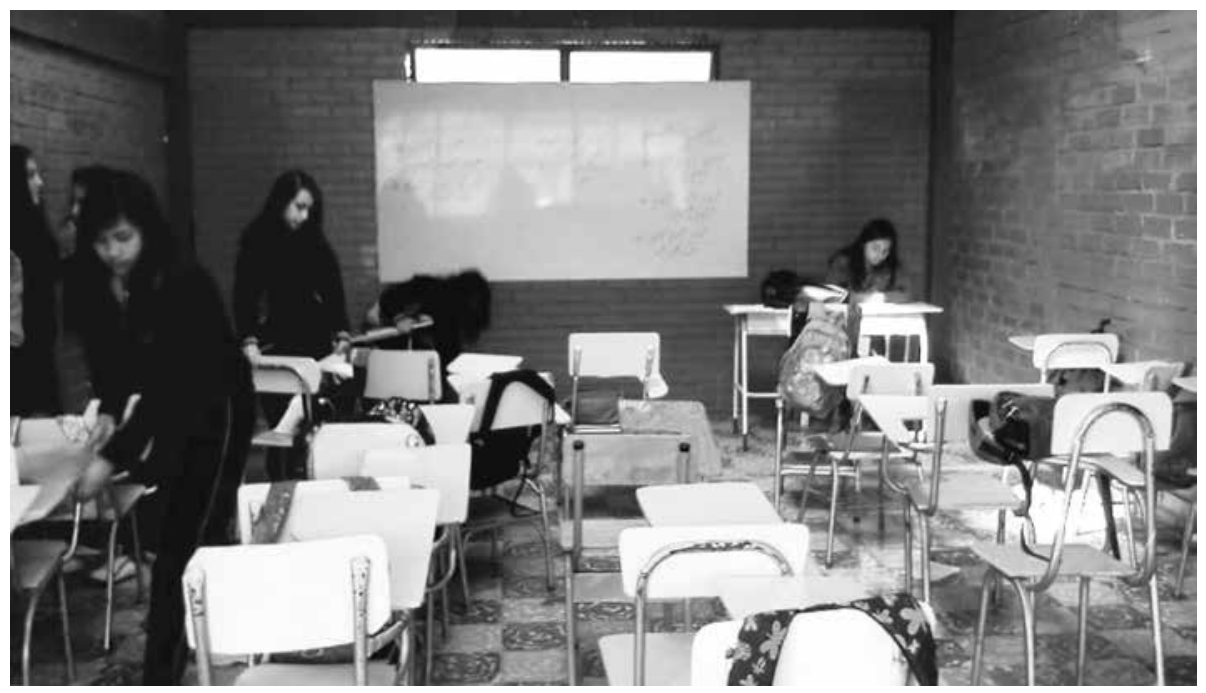

Figura 1. Aula.

Fuente: Esta investigación.

De lo anterior, Loughlin \& Suina señalan que "algunos profesores actúan como si al emplear un determinado mueble de un modo especifico, eso significaría que cualquier otro elemento debería ser utilizado precisamente de la misma manera. Así, todas las mesas se hallan reservadas para tareas de papel y lápiz: todas se ordenan en filas, en cuadros, en círculo o aislados; todas las estanterías se alinean a lo largo de las paredes. Una disposición más flexible del espacio y de los muebles puede servir más eficazmente a las actividades de aprendizaje de los niños"19.

Los autores hacen referencia en que la organización y distribución del mobiliario en el aula no debe ser rigurosa, sino por el contrario es importante cambiar la organización y distribución espacial del mobiliario en el aula, de tal manera que se aprovechen todos los espacios disponibles para llevar a cabo el proceso educativo y donde la prioridad sea la comodidad de los estudiantes, ya que al sentirse en un ambiente cómodo se promueve la concentración y el interés por aprender.

19. Loughlin y Suina, El ambiente de aprendizaje: Diseño y organización, 50. 

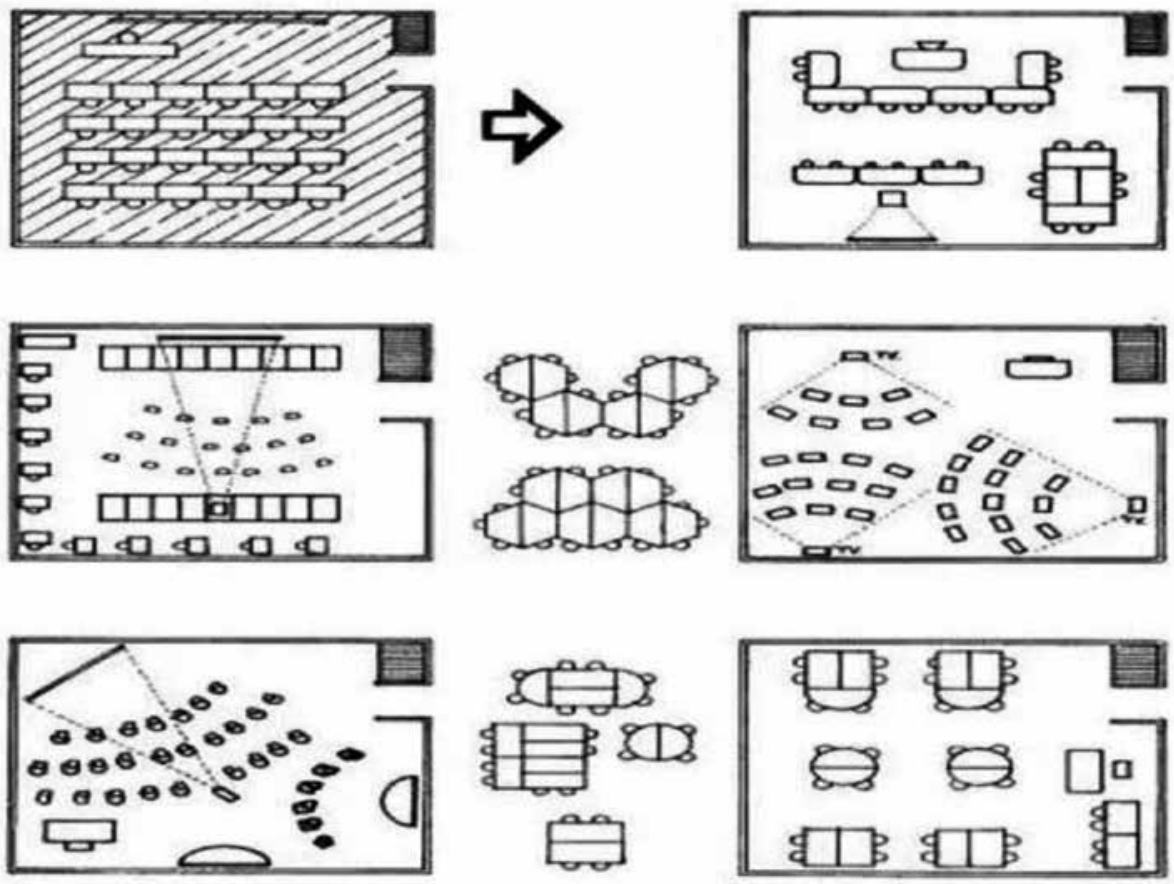

Figura 2. Reorganización del espacio escolar según actividades a realizar.

En cuanto a los laboratorios, estos se caracterizan por presentar mesones que poseen una estructura fija, dispuestos en fila en la parte central del laboratorio, con una distancia de aproximadamente un metro, espacio en el cual se encuentran ubicados los bancos para cada estudiante, esto hace que el docente y los estudiantes puedan desplazarse alrededor de los mesones, sin embargo, el espacio del laboratorio de física se encuentra reducido por la presencia de pupitres. En este sentido, Gaviño et al. (1994), mencionan que:

"La amplitud del recinto dependerá del número de alumnos a que se destinen, de tal manera que permita el transito libre por todo el laboratorio, [...] debe estar provisto de mesas de trabajo con sus respectivos bancos para alumnos. Se recomiendan mesas para grupos pequeños, situadas de manera que pueda circularse en torno a los alumnos sin obligarles a levantarse, permitiendo, además, el acceso inmediato del profesor a cualquier mesa"20.

En consecuencia, la disposición del mobiliario en los laboratorios debe permitir facilidad de acceso y movilidad de docentes y estudiantes, por ello es recomendable que "sus instalaciones y sus mesones fijos deberán ser perimetrales

20. Gaviño Gonzalo et al., Técnicas biológicas selectas del laboratorio y de campo, 14. 
con el fin de dejar el espacio central libre para distintas formas de distribución de mesas y sillas"21, dando libertad al estudiante para ubicarse en el espacio donde él considere oportuno para realizar las actividades de experimentación.

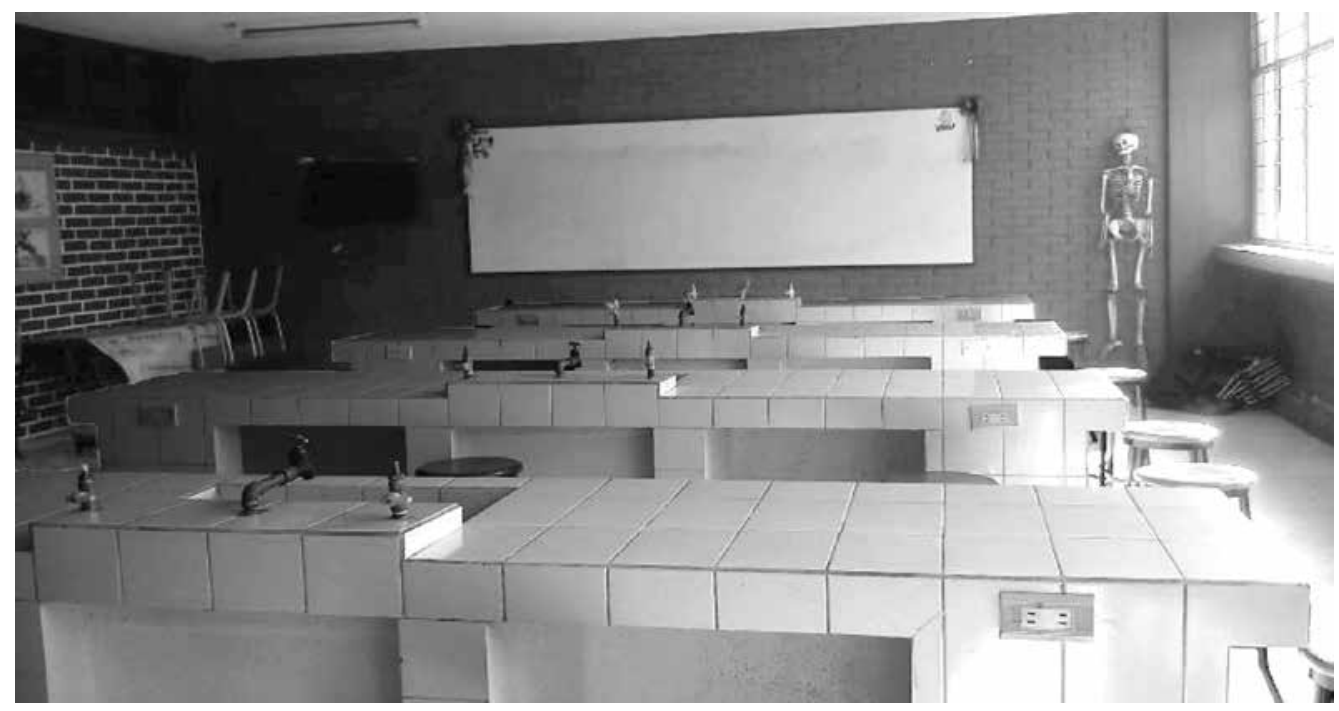

Figura 3. Laboratorio de ciencias naturales.

Fuente: Esta investigación.

\section{Recursos didácticos de los escenarios pedagógicos}

El aula de clase y el laboratorio se prestan como escenarios para llevar a cabo el proceso de enseñanza-aprendizaje de las ciencias naturales, por ello deben poseer diversidad de recursos didácticos, los cuales se definen como:

"Cualquier instrumento u objeto que puede servir como recurso para que mediante su manipulación, observación o lectura se ofrezcan oportunidades de aprender algo, o bien con su uso se intervenga en el desarrollo de alguna función de la enseñanza", al respecto los autores infieren que los materiales curriculares comunican contenidos para su aprendizaje y pueden servir para estimular y dirigir el proceso de enseñanza-aprendizaje, total o parcialmente"22.

En las aulas se observa recursos como el tablero, el cual cumple una función esencial en el proceso formativo, Borda \& Páez (1997) lo definen como: “un

21 Álvaro Rivera y Asociados Ltda. Estándares para el planeamiento, diseño y especificación de construcciones escolares Secretaría de Educación Distrital (2000), https://www.udistrital.edu.co/ files/contratacion/ciudadela- orvenir/estandaresBasicosEscolares.pdfs (16 de octubre del 2015).

22. Juan Méndez, "El papel de los materiales curriculares en la intervención educativa", Revista de Educación. Universidad de Huelva (2001), http://www.uhu.es/publicaciones/ojs/index.php/xxi/ article/viewFile/593/899. (15 de agosto de 2014). 
elemento permanente en el aula de clase, con el que se grafica con tiza con el fin de explicar el tema"23. En este sentido, el tablero es un recurso que le sirve al docente para el desarrollo de sus clases y al estudiante para efectuar actividades de aprendizaje y visualizar contenidos y explicaciones. De la misma forma, las carteleras representan un recurso valioso, ya que en ellas se presenta diversidad de información que puede ir acompañada de imágenes o distintos gráficos, facilitando la comprensión de los contenidos de ciencias naturales. En este sentido la cartelera se define como: "un estampado en cartulina u otro material, se incluyen aquí los dibujos, carteles, historietas, caricaturas, gráficos, esquemas que tiene tanta importancia en la escuela"24.

Por otra parte, los recursos didácticos que se encuentran en los laboratorios se clasifican de acuerdo al uso y tipo de material de fabricación, esto en el caso del laboratorio de ciencias naturales donde se evidenció la presencia de materiales de tipo: volumétricos, calentables, para medición de densidad, temperatura, materiales de vidrio, de madera, de metal, inflamables, utensilios de sostén, material de filtración, reactivos, microscopios, los cuales son utilizados para el desarrollo de actividades que involucran proceso químicos y biológicos.

Finalmente, cabe destacar que las condiciones físicas, la organización y distribución de los recursos didácticos influyen en los procesos de enseñanzaaprendizaje, puesto que se generan oportunidades y ambientes de aprendizaje propicios para llevar a cabo el desarrollo de dicha área y a la vez, permite el desarrollo de procesos específicos de las ciencias naturales, donde tanto docente como estudiante tienen la facilidad de confrontar los conocimientos y contextualizar su aprendizaje. Así pues, los autores Montagner \& Crahay (citados en Cerda) "demostraron el grado de incidencia que tiene en el trabajo pedagógico el tipo de mobiliario que se utiliza. Sillas y mesas incomodas, no funcionales, tableros inadecuados, la iluminación deficiente, elevado nivel de ruidos, temperaturas demasiado altas o bajas, falta de ventilación y otros, son aspectos que influyen en el desarrollo de actividades cotidianas de una clase. Los autores pudieron comprobar las diferencias existentes en el rendimiento escolar de los alumnos asistentes a aulas que reunían las condiciones físicas y ambientales adecuadas para el trabajo escolar, de otros que lo hacían a aquellas que estaban muy lejos de serlo"25.

Por otra parte, la calidad y disposición de los recursos que presenten los escenarios pedagógicos influyen en el desarrollo de las actividades de enseñanza que plantea el docente y en el interés que se despierta en el estudiante para su aprendizaje; así las cosas, cuando los recursos se encuentran en adecuadas

23. Elizabeth Borda y Elizabeth Páez, Ayudas educativas: creatividad y aprendizaje (Santafé de Bogotá: Cooperativa Editorial Magisterio, 1997), 179.

24. Borda y Páez, “Ayudas educativas: creatividad y aprendizaje”, 189.

25. Hugo Cerda, Proyecto de aula: el aula como un sistema de investigación y construcción de conocimientos. (Santafé de Bogotá: Cooperativa Editorial Magisterio, 2001), 25. 
condiciones permiten el desempeño eficaz del docente y estudiante y se promueve la utilización frecuente de estos.

\subsection{Estrategias de enseñanza en los escenarios pedagógicos}

Mediante las técnicas de entrevista y observación directa dirigidas a estudiantes de grado noveno y profesora de ciencias naturales de la Institución Educativa Liceo Central de Nariño, se identificó las estrategias didácticas utilizadas para la enseñanza de esta área, los recursos empleados y se reconoció las percepciones de los estudiantes respecto a cómo se enseña, del mismo modo se resaltaron las actividades que resultan significativas para ellos a la hora de aprender, como se muestra en la siguiente figura:

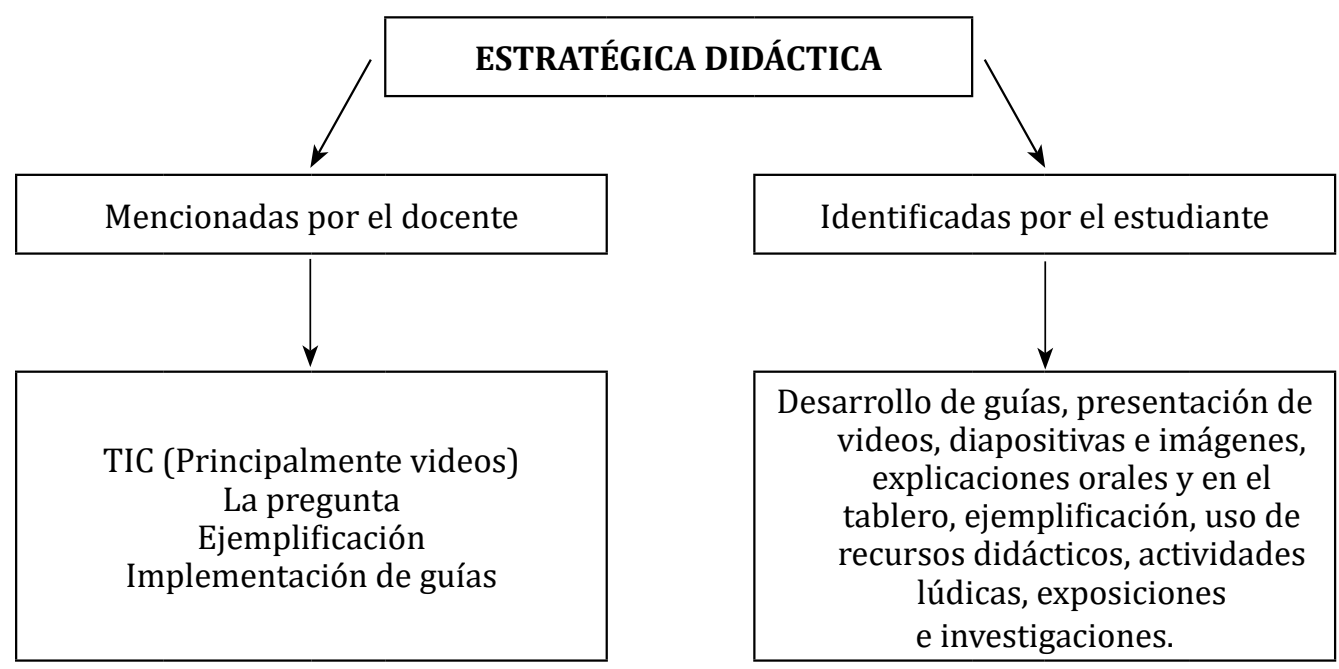

Figura 4. Resultado de entrevista.

Fuente: esta investigación.

A partir del esquema, las principales estrategias utilizadas en el aula de clase son: la ilustración, la pregunta y la exposición, destacándose entre los recursos didácticos la utilización de las TICs (Tecnologías de la información y comunicación) que incluye presentación de videos, diapositivas e imágenes y la implementación de guías.

Con respecto al uso de las TIC para la enseñanza- aprendizaje de las ciencias naturales, Cabrera \& Chaves mencionan que éstas "son técnicas que hacen parte de la estrategia de enseñanza denominada "ilustración" que consiste en "la representación visual de los conceptos, objetos o situaciones de una teoría o tema 
específico"26. El video es el más utilizado como recurso didáctico y se caracteriza por presentar de manera audiovisual la información, lo cual cautiva e induce al estudiante hacia el aprendizaje, puesto que muestra un contenido de manera visible, según Medina \& Salvador el video permite "poner al alumno directa o indirectamente ante la experiencia de aprendizaje" 27 , de tal manera que sea significativo, en relación a esto los estudiantes manifiestan que la presentación de videos "hace que aprendan más" (E7G91) ${ }^{28}$ y “entiendan mejor" (E1G92)29.

El video también se puede utilizar como actividad para motivar al estudiante, desarrollar una temática, hacer síntesis y aclarar conceptos, ya que "permite el rebobinado, la congelación de imágenes, siendo la posibilidad de repetición su principal cualidad al permitir al alumno trabajar a su propio ritmo y reiterar las informaciones a gusto del usuario"30.

Igualmente, la ejemplificación es reconocida por los estudiantes y hace parte de las técnicas de la "exposición", dentro de las cuales están inmersas la explicación oral y escrita que permiten la interacción mutua entre docente-estudiante, así pues, la explicación se caracteriza por ser:

"Una plática que planea el maestro para aclarar cualquier idea, procedimiento o proceso que el estudiante no ha comprendido. Todo maestro al igual que todo alumno, conoce la importancia de explicar con claridad [...] Es necesario el empleo de la aclaración tanto oral como escrita"31.

De este modo la explicación oral y/o escrita resulta una actividad significativa para los estudiantes puesto que la explicación realizada por la docente se caracteriza por ser clara y comprensible, donde resulta fácil entender y aprehender la temática, de ello los estudiantes plantean que la docente; "Explica de una manera en que casi todos entendemos" (E4G93) ${ }^{32}$, permitiendo que "se quede en el cerebro y no en un escrito" (E6G94) ${ }^{33}$, siendo así una actividad que resulta "muy interesante, pero luego toca escribir" (E6G94) ${ }^{34}$, en este caso cabe destacar que algunos estudiantes prefieren las explicaciones de la docente antes que la toma de apuntes, hecho que puede influir en el aprendizaje del estudiante, pues la toma de apuntes permite:

26. Lorena Cabrera y Elizabeth Chaves, Estrategias de enseñanza (Perú: Universidad Nacional Pedro Ruiz Gallo, 2011), http://es.slideshare.net/joanguibrings/clasificaciones-y-funciones-de-las-estrategiasde-enseanza (12 de mayo de 2015).

27. Antonio Medina y Francisco Salvador. Didáctica General (Madrid: Editorial Pearson Educación, S.A., 2009), 203.

28. Testimonio estudiante de grado $9-1$.

29. Testimonio estudiante de grado 9-2.

30. Medina y Salvador, "Didáctica General”, 210.

31. James Cooper, Estrategias de enseñanza: Guía para una mejor instrucción (México. D.F: Editorial Limusa. S.A., 2004), 146.

32. Testimonio estudiante de grado 9-3.

33. Testimonio estudiante de grado 9-4.

34. Testimonio estudiante grado $9-4$. 
"Mejorar la comprensión, haciendo el tema más interesante con el incremento en motivación que ésta genera [...] pues, las palabras si no se escriben se olvidan rápidamente así que es muy útil tomar apuntes, pues al no estar todo lo que dice el profesor en los libros, si no se escribiera lo importante de lo que dice en la clase perderíamos información que de otro modo sería difícil de conseguir"35.

Por lo tanto, el no tomar apuntes puede interferir de algún modo en la comprensión de las temáticas, como dice el autor los estudiantes pueden perder información valiosa para su aprendizaje.

Continuando con la ejemplificación resulta que es una técnica empleada para aclarar las dudas del estudiante al momento de explicar conceptos o procedimientos, en este sentido la docente menciona que "sitúa en el contexto del estudiante, mediante la ejemplificación y busco el contexto donde ellos pueden mirar cercano el tema a su vida"36, por lo tanto se infiere que presenta ejemplos relacionados con la vida cotidiana a fin de que el concepto sea relacionado con algo que los alumnos ya conocen, frente a esto los estudiantes reconocen que los ejemplos son "de la vida cotidiana" (E12G94) ${ }^{37}$, manifestando también que "son muy claros" (E8G91) ${ }^{38}$, permitiendo la comprensión de la temática. Respecto a esto, Shostali (citado en Cooper) menciona que es posible:

"Aumentar la comprensión y la aplicación de ideas abstractas por medio del uso de ejemplos y analogías. Para los estudiantes puede ser difícil entender una idea o un principio abstracto. Más aún, muchos estudiantes que comprenden bien una idea o un principio, tienen dificultad para aplicar su conocimiento a nuevas situaciones. Cuando un maestro utiliza adecuadamente ejemplos y analogías puede contribuir enormemente a superar dichas limitaciones".39

Mediante la observación de clases se identificó que la ejemplificación es aplicada por la docente en la mayoría de las clases y la utiliza fundamentalmente para dar a conocer las aplicaciones de las ciencias naturales en aspectos tecnológicos, ambientales y culturales, a fin de lograr la comprensión de los diferentes contenidos que involucran procesos físicos, químicos y biológicos.

La pregunta constituye una estrategia protagonista en cada clase desarrollada. Se reconoce que la docente inicia las temáticas con una pregunta que tendrá respuesta a lo largo de la clase, la cual es dinamizada por el tipo de incógnitas que se formulan; además la docente afirma que "La estrategia principal es la pregunta para llevar al estudiante a desarrollar interrogantes, a la necesidad de buscar más información, a interrelacionar unos conocimientos con otros"40. Así, la pregunta se caracteriza por relacionar la temática con la cotidianidad del estudiante, de tal

35. Inés Carreño, Metodologías de aprendizaje (Madrid: Quebecor World Perú. Editorial MMVIII, s.f.), 166.

36. Testimonio docente de ciencias naturales de grado noveno.

37. Testimonio estudiante grado $9-4$.

38. Testimonio estudiante grado 9-1.

39. Cooper, "Estrategias de enseñanza: Guía para una mejor instrucción”, 140.

40. Testimonio docente de ciencias naturales de grado noveno. 
manera que él no crea que le hablan de algo ajeno a su realidad. Para Hernández (2003) la pregunta como estrategia:

"Es indispensable para despertar la curiosidad de los niños y las niñas y desarrollarlos como investigadores [...] Además propicia la reflexión, hace recordar o repasar un acontecimiento pasado. Las conversaciones a través de preguntas sirven para darse cuenta de una dificultad o de un avance que están teniendo los estudiantes. Resulta sumamente necesaria para establecer interacción en el aula"41.

La pregunta permite captar la atención del estudiante y fortalecer la participación en clase, de esta manera se motiva, atrae e invita al estudiante hacia la disposición por aprender. Además, esta técnica genera un ambiente de reciprocidad entre los actores del proceso educativo, puesto que con las intervenciones y con los diferentes puntos de vista tanto estudiantes como docente aprenden y promueven un intercambio de conocimientos a partir de las experiencias vividas.

Se encontró que las guías que emplea la profesora en cada temática son diseñadas por ella misma y se caracterizan por contener los conceptos claves del tema, gráficos, consultas de profundización y preguntas de análisis, así pues, "las guías didácticas constituyen un recurso que tiene el propósito de orientar metodológicamente al estudiante en su actividad independiente, al mismo tiempo que sirven de apoyo a la dinámica del proceso docente, guiando al alumno en su aprendizaje, favorecen este proceso y promueven la autonomía a través de diferentes recursos didácticos como son: explicaciones, ejemplos, comentarios, esquemas, gráficos, estudio de caso y otras acciones similares a las que el profesor utiliza en sus actividades docentes" ${ }^{\prime 2}$.

En ese sentido, se infiere que las guías didácticas son un recurso que orientan el proceso de aprendizaje de los estudiantes, puesto que presentan pautas orientadoras, invitan al estudiante a la lectura, a la indagación, comprensión, análisis y reflexión de situaciones pertinentes al tema de estudio. Por su parte, la docente plantea que "el contenido que se coloca es mínimo, pero más es el problema, la pregunta o el caso que tiene que resolver y además se coloca los estándares a desarrollar, la forma de evaluación y las competencias a desarrollar en el hacer, ser y saber durante cada periodo, de tal manera que el estudiante conozca cuales son las actividades que se van a desarrollar durante el periodo"43.

Con base en el testimonio de la docente, las guías son recursos fundamentales para el estudiante, puesto que muestran todos los aspectos que se incluyen en el

41. Rose Hernández, Mediación en el aula. Recursos, estrategias y técnicas didácticos cuadernos para la enseñanza del español (Editorial Universidad Estatal a distancia, 2003), https://books.google.com.co/ books?id=ge0p0brzRH4C\&printsec=frontcover\#v=onepage\&q\&f=false (04 de julio de 2015).

42. Ignacio García y Graciela De la Cruz Blanco, Las guías didácticas: recursos necesarios para el aprendizaje autónomo, Edumecentro, Vol. 6. No. 3 (2014): 166, http://scholar.googleusercontent. com/scholar?q=cache:dxUY5K-l2UUJ:scholar.google.com/\&hl=es\&as_sdt=0\%2c5 (16 de junio de 2015).

43. Testimonio docente de ciencias naturales de grado noveno. 
desarrollo de las clases, así el estudiante se mantiene al tanto del proceso que se desarrollará en función de su aprendizaje.

De la misma manera la docente afirma que "las guías le permiten a uno como docente tener claridad en que va hacer con el estudiante y al mismo estudiante que se le va a enseñar, para qué, y que se le va a evaluar que también es bien importante. Por esta razón las guías se entregan al inicio de periodo"44, las guías no solo constituyen un recurso para la aplicación, sino como ella lo resalta, están diseñadas para orientar el proceso que el profesor adelanta con los estudiantes.

En cuanto al laboratorio, se encontró que este escenario no es utilizado para el desarrollo de las clases de ciencias naturales, frente a ello la docente argumenta que el trabajo en el laboratorio se dificulta debido al número de estudiantes, el manejo de materiales de riesgo y a los casos de indisciplina que se pueden presentar, sin embargo, la docente propone como posibles estrategias a desarrollar en este escenario el planteamiento de hipótesis, la pregunta, la ejemplificación y el desarrollo de guías. En esta parte se hace hincapié en el planteamiento de hipótesis y desarrollo de guías; con respecto a la primera la docente dice que "a partir de las hipótesis se genera en el estudiante un proceso consciente" 45 . En relación al planteamiento de hipótesis Ramírez 1991 reconoce que:

"Son las formas del desarrollo de las ciencias, a ellas, les corresponde ejecutar un papel de extraordinaria importancia en el desarrollo del conocimiento científico. La observación, la suposición y la comprobación de éstas constituyen el desarrollo general del pensamiento científico"46.

La docente argumenta que mediante el planteamiento de hipótesis el estudiante desarrolla la habilidad de pensamiento, capacidad de observación y análisis. En cuanto a las guías señala que su contenido y estructura son diferentes, pues deben contener las pautas para desarrollar un practica experimental, conceptos y definir el rol que cada estudiante tiene (monitor, relator e integrante) de tal manera que todos trabajen en equipo.

En cambio, los estudiantes sugieren que la estrategia a emplearse en el laboratorio debe ser el desarrollo de experimentos, ya que para ellos resulta ser "una experiencia linda", que permite "más comprensión", "poner en práctica lo aprendido" siendo posible "observar lo sucedido y decir qué pasaría".

De ahí que, las prácticas de laboratorio resultan ser una experiencia de aprendizaje donde el estudiante puede observar y tener contacto directo con un fenómeno ya estudiado o desconocido para él, así mismo podrá comprobar hipótesis y comparar resultados junto con sus compañeros, esto genera espacios de participación activa y trabajo colaborativo, permitiéndole al estudiante evidenciar y comprender los conceptos trabajados en el aula de clase.

44. Testimonio docente de ciencias naturales de grado noveno.

45. Testimonio docente de ciencias naturales de grado noveno

46. Napoleón Ramírez, Metodología de la enseñanza de la química (Universidad Distrital Francisco José de Caldas: Fondo Editorial, 1991), 32. 


\section{El papel de los escenarios pedagógicos}

Además de las estrategias ya mencionadas que se emplean para el desarrollo de las temáticas de ciencias naturales, también se posibilita en estos escenarios el desarrollo de otras estrategias que permiten la integración e interacción de los actores pedagógicos, fomentado la libre expresión, el respeto y autonomía a la hora de participar; estas relaciones se llevan a cabo entre estudiante-docente y estudiante-estudiante. Partiendo de los hallazgos de la investigación se encuentra que para la docente el aula se convierte en "un espacio para la interacción entre compañeritos, para el diálogo, para analizar situaciones de la vida cotidiana y poder desde ahí proyectarlos a la realidad"47.

Respecto a la interacción entre estudiantes, ésta se desarrolla a través del trabajo en grupo, que permite fomentar en el estudiante el compañerismo, la capacidad de relacionarse con el otro mediante el diálogo y el respeto ante las diferencias de opinión. Así pues, "El dialogo en el aula abarca la participación de los estudiantes, ya sea como grupo en su totalidad o en subgrupos más pequeños para propiciar la discusión, el intercambio de opiniones y experiencias acerca de temas de estudio y de interés general. El diálogo representa una de las vías para la participación escolar, la que resulta imprescindible cuando se busca un aprendizaje significativo y de calidad" $\mathbf{4 8}$.

A pesar de que el laboratorio no es utilizado, la docente reconoce que "se presta como un espacio para evidenciar realidades y para la contextualización de los conceptos"49. Así, se infiere que al momento de enseñar es necesario tener en cuenta el contexto en el que vive cada uno de los estudiantes, a partir de ello el docente tratará de contextualizar las temáticas planteadas a fin de acercar al estudiante al conocimiento científico de manera sencilla y comprensible, por lo tanto al desarrollar una temática "se asume el contexto educativo al que se dirige, las características del grupo-clase donde se pondrá en marcha y las peculiaridades de los alumnos, individualmente considerados"50.

En consecuencia, el aula de clase y el laboratorio se prestan como espacios para el desarrollo de habilidades interpersonales, de manera que se fortalece la interacción entre estudiantes a través del diálogo sobre situaciones de la vida cotidiana.

\section{Desarrollo de competencias en los escenarios pedagógicos}

En este aspecto se hace alusión a las competencias que la docente pretende desarrollar con la aplicación de las estrategias antes descritas. En el aula de clase

47. Testimonio docente de ciencias naturales de grado noveno.

48. Ivet García, El diálogo: Un instrumento para la reflexión y la transformación educativa (s.f.), http://bibliotecavirtual.clacso.org.ar/ar/libros/cuba/cips/caudales05/Caudales/ARTICULOS/ ArticulosPDF/0524G093.pdf (12 de octubre de 2015).

49. Testimonio docente de ciencias naturales de grado noveno.

50. Medina y Salvador, "Didáctica General", 116. 
"por ejemplo, cuando se propone la indagación, cuando se le enseña hacer un proceso ordenado a partir de una lógica"51, así mismo, la docente plantea que existe una competencia importante denominada el uso del conocimiento científico, que permite comprender la importancia que tiene el estudio de las ciencias naturales para la vida, es decir, "la capacidad para comprender y usar nociones, conceptos y teorías de las ciencias en la solución de problemas, así como de establecer relaciones entre conceptos y conocimientos adquiridos sobre fenómenos que se observan con frecuencia" ${ }^{2}$.

Se encontró que las competencias desarrolladas en el aula de clase comprenden el saber conocer, saber hacer y el saber ser:

Saber conocer - - - desarrollo de pensamiento científico

Saber hacer - - - - comprensión de lecturas, exposición y análisis de fenómenos

Saber ser - - - - - - compañerismo, la comunicación y el trabajo en equipo.

También, se resalta las competencias de argumentación e interpretación, pues la docente sustenta que estas se logran desarrollar en el aula, empleando estrategias que invitan al estudiante a reflexionar, analizar y dar a conocer sus conocimientos.

\section{Estrategias y recursos significativos para el aprendizaje de las ciencias naturales}

En cuanto a las estrategias y recursos que resultan significativos para los estudiantes, se encuentra la experimentación, trabajo en equipo, guías de apoyo, actividades lúdicas, uso de recursos didácticos y tecnológicos, explicaciones, ejemplos, lecturas y también los trabajos extra clase.

Teniendo en cuenta lo anterior, se infiere que los estudiantes respondieron conforme a sus preferencias, de ahí la habilidad del docente al planear las estrategias es importante, ya que debe tener en cuenta las diferentes formas de aprendizaje que tiene sus estudiantes.

Conviene mencionar la percepción que tienen los estudiantes sobre los experimentos en el laboratorio, señalando que: "se aprende más mirando, podemos identificar los procesos, se comprueba lo enseñado, porque una persona entiende más con la vista y el oído que solo escribir"53.

De lo expuesto, se dice que el estudiante se motiva al aprender haciendo, dado que pasa de ser un agente pasivo a ser un agente activo, pues en la experimentación el estudiante tiene un mayor protagonismo en el aprendizaje y puede contribuir al

51. Testimonio docente de ciencias naturales de grado noveno.

52. Reinaldo Bernal, Sistema nacional de evaluación estandarizada de la educación. Alineación del examen Saber, 11. (2013), http://www.icfes.gov.co/docman/instituciones-educativas-y-secretarias/ saber-11/novedades/651-alineacion-examen-saber-11/file?force-download=1 (13 de octubre de 2015).

53. Testimonios estudiantes grado noveno. 
desarrollo de distintas habilidades de aprendizaje. Bastidas et al (citado en Banet), señala que "estas actividades no sólo estarían relacionadas con el aprendizaje de destrezas y técnicas específicas de laboratorio, sino también con el desarrollo de actitudes y de habilidades cognitivas de alto valor intelectual"54.

De igual manera, se reconoce que los trabajos en equipo son una actividad significativa para muchos estudiantes, "ya que hay más unión entre compañeros y más entendimiento, porque analizó con mis compañeros y me pueden corregir si me equivoco, porque nos podemos ayudar unos a otros, porque así compartimos ideas y conocemos nuevas cosas" 55 .

En consecuencia, el trabajo en equipo les permite apoyarse en sus compañeros, esto constituye una semejanza hacia el aprendizaje colaborativo, que según Leighton (citado en Cooper), lo caracteriza su "combinación particular de objetivos grupales o recompensas en equipo, de responsabilidad individual, y de oportunidades iguales para lograr el éxito"56. Esta actividad es planteada por la docente con el objetivo de que se apoyen entre compañeros y así lograr un aprendizaje grupal.

Por otra parte, cabe resaltar las razones que los estudiantes exponen para trabajar de manera individual. "porque puedo concentrarme más y dar lo mejor de mi" (E6G9) ${ }^{57}$. No obstante, los estudiantes reconocen que trabajar de las dos maneras es importante y pertinente eso basándose en la naturaleza de la actividad que la docente proponga para lograr su aprendizaje. Así pues, los estudiantes dicen que "según como sea, por ejemplo, si necesitas ayuda es necesario un equipo, pero individual también es bueno porque no tienes oportunidad de distraerte" (E8G91) ${ }^{58}$.

También son un recurso valioso las guías de apoyo, en la medida que se caracterizan por "no tener tanta teoría", "permiten aprender más y conocer mejor el tema". Se identifica que los estudiantes se sienten cómodos cuando la docente utiliza técnicas como las actividades lúdicas, "porque por medio de la participación fluyen las ideas, aunque también me gustaría las clases afuera" (E7G94) ${ }^{59}$. En este sentido conviene hablar de pedagogía lúdica, donde:

"Un aspecto es el aprovechamiento de cualquier espacio lúdico o de disfrute como oportunidad de aprendizaje y un segundo elemento es la flexibilización metodológica del proceso enseñanza aprendizaje, diseñando experiencias

54. Enrique Banet. Actividades prácticas en la enseñanza universitaria: Ciencias Experimentales y de la Salud (España: Universidad de Murcia, s.f.), https://www.um.es/c/document_library/get file?uuid=aaadc037-5ec2-4fff-9ea1-e8f95bdf52ae\&groupId=316845. (05 de septiembre del 2015).

55. Testimonios estudiantes grado noveno.

56. Cooper, "Estrategias de enseñanza: Guía para una mejor instrucción”, 457.

57. Testimonios estudiantes grado noveno.

58. Testimonio estudiante grado $9-1$.

59. Testimonio estudiante grado 9-4. 
agradables para el niño como "pretexto" para el abordaje y/o aproximación a conocimientos formales, necesarios, propios de la educación básica"60.

Además, las actividades lúdicas se presentan como un factor que influye en la motivación de los estudiantes, ya que puede aportar experiencias agradables que despiertan el interés por aprender y hacen que el desarrollo del proceso de enseñanza- aprendizaje no sea monótono sino dinámico e interactivo.

Sin embargo, aunque la mayoría de los estudiantes se inclinan por las actividades prácticas, algunos prefieren las actividades teóricas, por ejemplo: "porque entiendo mejor y como dicen la explicación es la que vale" (E8G94)61.

Con base en estas respuestas, se infiere que para los estudiantes las actividades teóricas son aquellas en las que la docente se apoya de la explicación y exposición para dar a conocer los conceptos y teorías de las ciencias naturales, éstas son realmente necesarias ya que se debe tener un sustento teórico mediante el cual el estudiante se apropia de las bases conceptuales que le hacen falta para comprender los contenidos y también para poner en práctica, de tal modo que pueda experimentar y llegar a la comprensión de un tema.

Finalmente, muchos estudiantes se apoyan de actividades prácticas y teóricas, pues dicen que las dos se complementan; son necesarias las explicaciones y el hacer al momento de aprender, de ahí la importancia de experimentar para aprender desde la experiencia, con respecto a esto se menciona que "es necesario la teoría, pero también se necesita la práctica para exponer el proceso completo." (E3G93)62.

A manera de conclusión, en el proceso de enseñanza la docente tendrá en cuenta diversos factores que influyen directa e indirectamente en el aprendizaje de los estudiantes, por lo tanto al momento de planear la clase la docente será capaz de seleccionar las estrategias, recursos, actividades y técnicas pertinentes a la temática, atendiendo a las necesidades del contexto de cada uno de los estudiantes, además la enseñanza de las ciencias naturales se caracteriza por contextualizar al estudiante, por lo cual se enfatiza en la comprensión y explicación de los fenómenos presentes en el entorno, de ahí la importancia de utilizar estrategias como la ejemplificación y la indagación, las cuales invitan al estudiante a buscar e identificar los aportes de las ciencias naturales para su vida.

Así mismo, se infiere que las actividades planteadas por la docente para la enseñanza, contribuyen al aprendizaje del estudiante, puesto que estas actividades no sólo están enfocadas hacia el garante de los objetivos propuestos en el currículum, como la obtención de los aprendizajes conceptuales y cognitivos que

60. Gustavo Moreno, La lúdica en los procesos educativos infantiles: Un proceso reflexivo para las escuelas de formación deportiva (Universidad Tecnológica de Pereira I Seminario de Ciencias Aplicadas a las Escuelas de Formación Deportiva, 2003), http://blog.utp.edu.co/areaderecreacionpcdyr/ files/2012/07/La-L\%C3\%BAdica-en-los-Procesos-Educativos-Infantiles.pdf (5 de junio de 2015).

61. Testimonio estudiante grado $9-4$.

62. Testimonio estudiante grado 9-3. 
incluye la memoria, la atención, el lenguaje, percepción, la solución de problemas o inteligencia y la planificación, sino más bien, la docente busca que el estudiante aprenda relacionándose tanto con sus compañeros como también con el entorno que lo rodea.

\section{Conclusiones}

Las condiciones físico- ambientales de los escenarios pedagógicos, en este caso el aula de clases y laboratorios influyen en el ambiente de aprendizaje que se genera dentro de ellos, pues si presentan condiciones adecuadas habrá comodidad para los estudiantes, así como también es importante la disponibilidad de recursos y herramientas necesarias para llevar a cabo el proceso de enseñanza. Sin embargo, en la investigación realizada se encontró que las aulas presentan condiciones poco adecuadas a excepción de los laboratorios, los cuales cumplen con los requisitos mínimos para llevar a cabo el trabajo propio de las ciencias naturales.

Por otra parte, la distribución y organización del mobiliario y recursos presentes en los escenarios pedagógicos inciden en la movilidad y comunicación de los actores educativos, por ello es necesario que estos espacios presenten las características mencionadas por los autores, ya que de esa forma se contribuye a un buen aprendizaje y se facilita el trabajo del docente. Asimismo, se aprovecha los espacios disponibles para realizar diversas actividades didáctico-pedagógicas.

El aula de clase se presenta como el principal escenario donde se lleva a cabo los procesos educativos, lugar donde además de desarrollar los contenidos de manera teórica, posibilitándose la explicación de las temáticas, planteamiento de ejemplos, la movilización de conocimiento a través de la pregunta, la utilización de guías y recursos TIC, también permite la interacción entre estudiante y docente, sin embargo, en menor grado favorece el desarrollo de actividades experimentales.

En la actualidad es evidente propiciar escenarios pedagógicos que permitan la participación activa del docente y estudiantes, esto haciendo uso de diferentes recursos, herramientas, espacios y estrategias didáctico-pedagógicas donde se logre aprovechar las potencialidades y competencias de los alumnos, por esta razón es importante adecuar los espacios educativos a las necesidades de los estudiantes puesto que son ellos quienes conviven y pasan la mayor parte de su tiempo, por esto deben contar con la condiciones suficientes para garantizar la comodidad y aprendizaje de las diferentes áreas del conocimiento, en especial de las ciencias naturales. 


\section{REFERENCIAS BIBLIOGRÁFICAS}

Banet, Enrique, eds. Actividades prácticas en la enseñanza universitaria: Ciencias experimentales y de la salud. España: Universidad de Murcia, s.f, https://www.um.es/c/document_library/get_file?uuid=aaadc037-5ec24fff-9ea1-e8f95bdf52ae\&groupId=316845.

Bernal, Reinaldo. Sistema nacional de evaluación estandarizada de la educación. Alineación del examen Saber, 11. (2013), http://www.icfes.gov.co/docman/instituciones-educativas-y-secretarias/saber-11/ novedades/651-alineacion-examen-saber-11/file?force-download=1

Borda, Elizabeth y Páez, Elizabeth, Ayudas educativas: creatividad y aprendizaje. Santafé de Bogotá: Cooperativa Editorial Magisterio, 1997.

Cabrera, Lorena y Chaves, Elizabeth, eds. Estrategias de enseñanza. Perú: Universidad Nacional Pedro Ruiz Gallo, 2011, http://es.slideshare.net/joanguibrings/clasificaciones-y-funciones-de-las-estrategias-deenseanza.

Carreño, Inés. Metodologías de aprendizaje. Madrid: Quebecor World Perú. Editorial MMVIII, s.f.

Cerda, Hugo. Proyecto de aula: el aula como un sistema de investigación y construcción de conocimientos. Santa Fe de Bogotá: Cooperativa Editorial Magisterio, 2001.

Cooper, James. Estrategias de enseñanza: Guía para una mejor instrucción. México. D.F: Editorial Limusa. S.A, 2004.

Díaz, Mario. Metodologías de enseñanza y aprendizaje para el desarrollo de competencias: Orientaciones para el profesorado universitario ante el espacio Europeo de educación superior. Madrid: Alianza. Editorial S.A., 2006.

Duarte, Jakeline, eds. "Ambientes de aprendizaje. Una aproximación conceptual”, Estudios Pedagógicos. No. 29 (2003), http://www.scielo.cl/scielo.php?script=sci_arttext\&pid=S0718-07052003000100007.

Gallego, Rómulo y Pérez, Royman, La enseñanza de las ciencias experimentales: El constructivismo del caos. Santafé de Bogotá, D.C.: Cooperativa Editorial Magisterio, 1997.

García, Ignacio y De la Cruz Blanco, Graciela, eds. Las guías didácticas: recursos necesarios para el aprendizaje autónomo, Edumecentro, Vol. 6. No. 3 (2014), http://scholar.googleusercontent.com/ scholar?q=cache:dxUY5K-l2UUJ:scholar.google.com/\&hl=es\&as_sdt=0\%2c5

García, Ivet, eds. El diálogo: Un instrumento para la reflexión y la transformación educativa (s.f.), http://bibliotecavirtual.clacso.org.ar/ar/libros/cuba/cips/caudales05/Caudales/ARTICULOS/ArticulosPDF/0524G093. pdf

Gaviño, Gonzalo, Juárez, Carlos y Figueroa, Héctor. Técnicas biológicas selectas del laboratorio y de campo. México: Editorial Limusa, 1994.

Hernández, Rose, eds. Mediación en el aula. Recursos, estrategias y técnicas didácticos cuadernos para la enseñanza del español. Editorial Universidad Estatal a distancia, 2003. https://books.google.com.co/book s?id=ge0p0brzRH4C\&printsec=frontcover\#v=onepage \&q\&f=false

Herrera, Javier, eds. La distribución de los pupitres en el aula de clase. Pedagoviva. Santafé de Bogotá, Colombia, 2009, https://pedagoviva.wordpress.com/2009/08/03/la-distribucion-de-los-pupitres-en-el-aula-de-clasejavier-herrera-cardozo-bogota-mayo-2009/

Loughlin, Catherine y Suina, Joseph, El ambiente de aprendizaje: Diseño y organización. Madrid, España: Editorial Morata, S.L., 1995. 
Marland, Michael, eds. El arte de enseñar: técnicas y organización del aula. España: Morata, 2003, http:// books.google.com.co/books?id=dM4oerVJesMC\&printsec=frontcover\&dq=importancia+del+aula+en+la+la bor+educativa\&hl=es\&sa=X\&ei=676UUrh0eipsATp9YCIDQ\&ved=0CCwQ6AEwAA\#v=onepage\&q\&f=false.

Medina, Antonio y Salvador, Francisco, Didáctica General. Madrid España: Editorial Pearson Educación, S.A., 2009.

Medina, Jorge, eds. El malestar de la pedagogía. El acto de educar desde otra identidad docente. Argentina: Ediciones Novedades Educativas, 2006, https://books.google.com.co/books?id=HETribB9tIC\&pg=PA53\& $\mathrm{dq}=\mathrm{acto}+$ pedagogico\&hl=es419\&sa=X\&ved=0CBwQ6AEwAGoVChMI7YvpnZLMxwIVxtgeCh2JWATL\#v=o nepage\&q=acto $\% 20$ pedagogico\&f=false (22 de junio del 2015$)$.

Méndez, Juan, eds. "El papel de los materiales curriculares en la intervención educativa", Revista de Educación. Universidad de Huelva (2001), http://www.uhu.es/publicaciones/ojs/index.php/xxi/article/ viewFile/593/899.

Ministerio de Educación Nacional, eds. Lineamientos curriculares de las ciencias naturales y educación ambiental. Bogotá: Ministerio de Educación Nacional, 1998, http://www.mineducacion.gov.co/cvn/1665/ articles-89869_archivo_pdf5.pdf

Moreno, Gustavo, eds. La lúdica en los procesos educativos infantiles: Un proceso reflexivo para las escuelas de formación deportiva. Universidad Tecnológica de Pereira, I Seminario de Ciencias Aplicadas a las Escuelas de Formación Deportiva, 2003, http://blog.utp.edu.co/areaderecreacionpcdyr/files/2012/07/ La-L\%C3\%BAdica-en-los-Procesos-Educativos-Infantiles.pdf

Ramírez, Napoleón. Metodología de la enseñanza de la química. Universidad Distrital Francisco José de Caldas: Fondo Editorial, 1991.

Rivera, Álvaro y Asociados Ltda. Estándares para el planeamiento, diseño y especificación de construcciones escolares Secretaría de Educación Distrital, 2000, https://www.udistrital.edu.co/files/contratacion/ciudadela- orvenir/estandaresBasicosEscolares.pdfs

Titone, Renzo. Metodología didáctica. Madrid, España: Editorial RIALP, 1966.

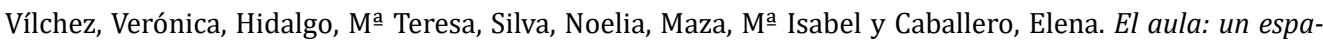
cio de posibilidades: Arte, educación y cultura. España: Colbaa, 2012, http://www.educacionartistica.es/ aportaciones/4_audiovisuales/402_silv_maz_hid_vilch_cab_aula\%20espacio\%20de\%20posibilidades.pdf 